\title{
Developing Realistic Designs for Wind Farms: Incorporation of an Imperialist Competitive Algorithm
}

\author{
Kaamran Raahemifar ${ }^{1}$, Marc A Rosen², Omid Rahbari ${ }^{3, *}$, Mohammad Hossein Morshed \\ Varzandeh $^{3}$, Majid Vafaeipour ${ }^{4}$ \\ ${ }^{1}$ Department of Electrical and Computer Engineering, Ryerson University, Toronto, ON M5B 2K3, \\ Canada.
}

${ }^{2}$ Faculty of Engineering and Applied Science, University of Ontario Institute of Technology, Oshawa, Ontario L1H 7K4, Canada.

${ }^{3}$ Young Researchers and Elite Club, South Tehran Branch, Islamic Azad University, Tehran, Iran.

${ }^{4}$ Department of Mechanical and Aerospace Engineering, Syracuse University, 263 Link Hall, Syracuse, NY 13244, USA.

E-Mails: Rahbari.omid@gmail.com

* Author to whom correspondence should be addressed; Tel.: +98-912-154-2571;

Received: 10 September 2014 / Accepted: 31 October 2014 / Published: 3 November 2014

\begin{abstract}
The optimal positioning of wind turbines plays an important role in acquiring the anticipated output power from wind farms. This paper addresses challenges related to typical restriction assumptions for turbine arrangements in wind farms with a candidate selection approach. A hybrid quadratic assignment problem-imperialist competitive algorithm (ICA-QAP) method with an initial candidate points' selection (ICPS) approach is applied to two case studies. This hybrid algorithm is used to obtain optimal layout designs in terms of maximum efficiency. The current study incorporates previously utilized indicators from the literature for wind farms, such as wake effects, turbine hub height, rotor diameter, and power losses, and proposes additional criteria such as load-bearing capacity of soil and its restrictions. This is done to make the method applicable for realistic cases, and to incorporate the comments of expert designers into the design process and results. The results indicate that the achieved optimal layout design provides superior performance of the farms compared to that provided in previous similar studies. An efficiency improvement of about
\end{abstract}


$5 \%$ is attained for the first considered case. In addition, a combination of Dijkstra's Minimum Spanning and K-means approaches is applied to reduce the length of cables in the farm by $664 \mathrm{~m}$ in the second studied case.

Keywords: Wind farm, Wind farm layout, Quadratic Assignment Problem (QAP), Imperialist Competitive Algorithm (ICA), Placement of wind turbine, Iran, K-mean, Dijkstra's Minimum Spanning Tree, Wind farm cable layout design

\section{Introduction}

Renewable energy is an attractive areas for policy makers because of the unpredictable market for fossil fuels and the effects on it of political factors as well as concerns about global warming. Recent technology developments have greatly reduced the cost of harvesting renewable energy, resulting in significant growth of wind energy utilization. The global capacity for wind energy generation surpassed 336,300 MW in 2014, which satisfies about $4 \%$ of the global energy demand. In the first half of 2014 , the capacity of wind energy rose by $5.6 \%$ (compared to $5.0 \%$ and $7.3 \%$ for the same period in 2012 and 2013, respectively) and by 13.1\% on an annual basis (mid-2014 in comparison with mid-2013) [1]. Figure 1 illustrates the growth in wind energy generating capacity for 2011-2014. The percentages in the figure are the growth of wind energy capacity for each half year, and prediction of wind energy generating capacity by the end of 2014 is shown by a different color.

Figure 1. Growth in global wind energy generating capacity (MW) [1]

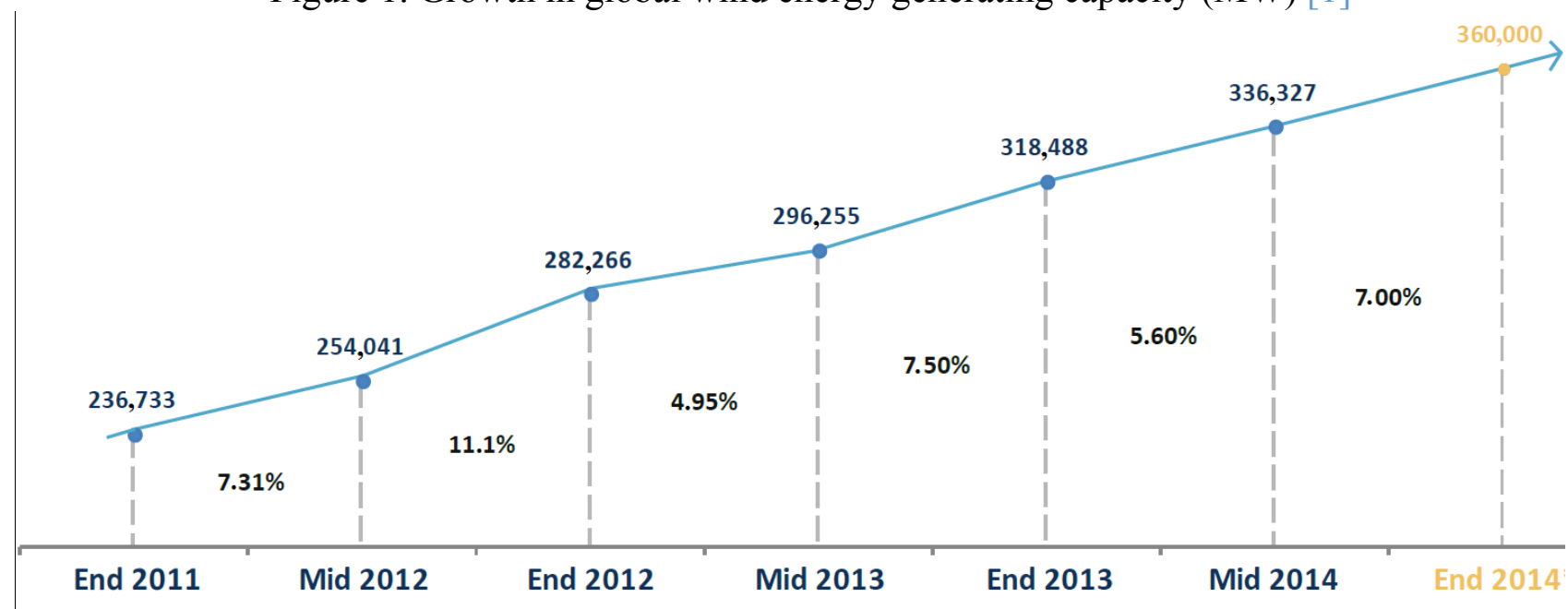

\subsection{Placement of wind turbines}

Optimizing the placement of wind turbines in a wind farm is an important step for achieving the maximum harvestable wind energy from a wind farm. Inefficient placement of turbines causes wind farms to perform worse than expected based on designs, due to wake effects, altered angles of attack, tower wakes and atmospheric turbulence. It has been shown that turbulence flow structures and wake effects can cause a 5 to 22 percent decrease in the efficiency of a wind farm [2]. Wake effects result in reductions of wind velocity and, therefore, lower electricity generation. Wake effects also increase wind turbulence, leading to unfavorable mechanical loads [3]. Addressing wake effects by appropriate placement of wind turbines not only can improve performance of a wind farm but also can 
significantly affect the economics. To illustrate, Figure 2 shows a schematic of the wake effect causing a decrease in wind speed. The red lines demonstrate a circumstance in which downstream wakes are created by an upfront wind turbine (left side) and reduce wind power. As illustrated, the turbulence fluctuations in the wake are recovered and turbulence intensity is decreased moving from left to right.

Figure 2. The wake of the rotor and recovering wake by increasing distance

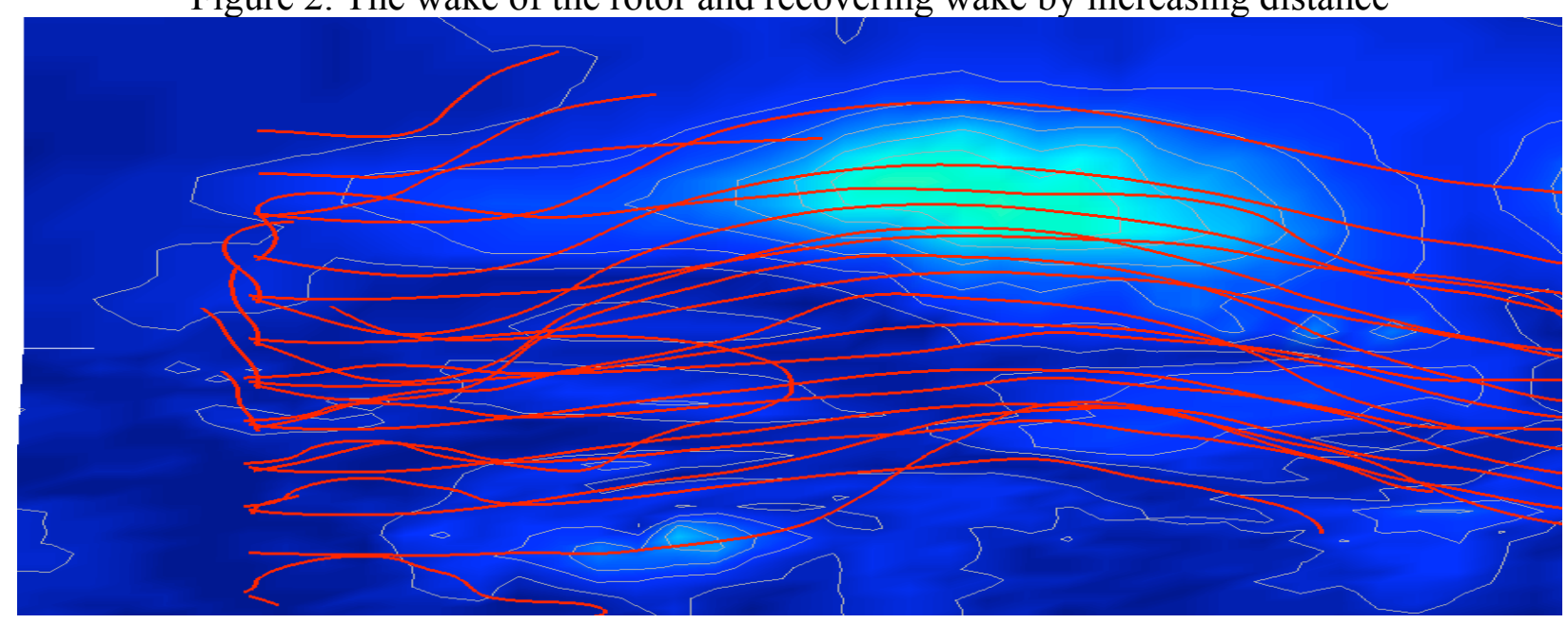

Investigations have been reported on assessing the layouts of wind farms through concentrating on such criteria as reducing power loss, land roughness and land availability. Most of the previous studies have utilized methods associated with linear models concentrating on optimizing the distance between turbines. In contrast with the earlier and more primitive studies, recent studies, due to complexity of designing wind farms and addressing all relevant factors, have demonstrated that other factors such as hub height, rotor diameter and load bearing play important roles [4]. Considering the complicated nature of these kinds of problems, meta-heuristic algorithms can play an important role.

Some valuable studies related to this issue have been reported. For instance, Salcedo-Sanz et al. [5] optimized an offshore farm in northern Europe by applying an evolutionary computation approach. Various layouts of turbines and free placements of turbines were assessed to achieve a highly efficient and viable design. The results demonstrated that the free placement of turbines, which are fixed in number, is superior compared to other applied scenarios. Saavedra-Moreno et al. [6] suggested a greedy evolutionary algorithm considering factors such as orography, wind velocity, installment cost, road construction between wind turbines and shape of wind farm, for maximizing the profit function. Rahbari et al. [4] applied a hybrid evolutionary approach, GA-QAP, to incorporate experts preferences into realistic designs of wind farm layouts taking into account prohibited installation areas. Through investigations of four cases and taking into account variable wind speed and direction, that study included in the design procedure such factors as wake effect, turbine hub height, rotor diameter and load-bearing capacity of soil. Grady et al. [7] applied a genetic algorithm for optimally designing the configuration of wind turbines. To attain this objective, the assessed function in the study was the ratio of cost to generated power. Perez et al. [8] suggested a new method for improving the efficiency of offshore wind farms by reducing wake effect and applied the method to a case study of a German offshore wind farm. The results showed that optimizing the layout of a wind farm based on the wake effect increases the efficiency more than $3.5 \%$. Eroglu and Seckiner [9] utilized an ant colony algorithm to maximize the energy generation by decreasing wake losses computed based on locations 
of turbines and wind direction to show the superior performance of ant colony optimization (ACO) for wind farms and the sensitivity of wake effect to the number of turbines.

\subsection{Power loss}

Even though the aforementioned factors such as wake effect and mechanical design of wind farms are important to the optimal placement of turbines [10], other criteria such as cable layout and accurate models of collector systems also play a significant role. Reducing voltage drops and power losses is one of the goals considered for designing of collectors, and is not associated with hub height and turbine model.

Researchers have shown that the power distribution system of an electric utility can account for up to 60 percent of its capital budget [12]. Moreover, an electric utility's power distribution system is considered more significant when 20 percent of its operation cost is an important expense [11], and optimization of the distribution system can decrease the cost by 5 to 10 percent [12].

The energy which is produced in wind farms is accumulated and transmitted to a substation via a collector system, which is a network of medium-voltage cables. Because of the long distances between wind turbines, the cable collector system typically used is over a hundred three-phase circuit kilometers [13]. Consequently, the overall reliability of the wind farm is dependent on the collector system. Moreover, the main part of the power losses result from the large and medium voltages of the collector system. In this regard, useful research has been reported. Dutta et al. [12] optimized the design of cable layouts in large scale wind farms in three steps. First, they applied a graph-theoretic minimum spanning tree to minimize the entire length of cables. Second, the length of cables is minimized based on the turbine numbers which are connected to the cable on feeders. Third, the direction and size of the power flow for various cables are calculated. Cheng and $\mathrm{Yu}$ [14] carried out a feasibility study for two onshore wind farms located in Taiwan. The difference between the wind farms are factors such as material of cables, the model of the transformers, and the length of buried cables. The outputs demonstrate that transmission losses and carbon dioxide emission can be decreased by $6.4 \mathrm{GW} \mathrm{h/year}$ and $4.5 \mathrm{kt} /$ year respectively by improving the structure and design of the cables. Geracia et al. [15] investigated the impact of the wind farm internal network on the exactness of the outputs. Moreover they suggested an aggregated model involving a mean value of a weight in which the transported power is considered a weighting factor to improve the accuracy of simulations associated with grid disturbances. Jadhav and Roy [16] examined the wake effect on economic dispatch using a bee colony approach for specifying the optimal production planning of thermal units. Then, the impact of wind velocity, wind shade area and distance between turbines on cost of fuel and transmission loss were investigated. Deng and Chen [17] discussed a transient function for an offshore wind farm with high voltage DC transmission. A case study was examined of a grid connection in which turbines are connected based on dc collection network. To reach the goal of withstanding voltage dips, the authors suggest a power-reduction control strategy. Meegahapola et al. [18] applied the capability of reactive power of a doubly fed induction generator (DFIG) associated with wind farms for optimization of the system losses, while observing the constraints of the network. They modified the IEEE-30 bus system by installing DFIG based wind farms in the medium voltage (MW) region which create three clusters in the network. Moreover, they demonstrated that DFIG is able to minimize the loss for various reactive power designs. Saiz-Marin et al. [19] assessed the impact of 
power loss due to expanding voltage control in a grid connecting wind farms to the transmission network, and the benefits and costs which extend from developing voltage control. Lumbreras and Ramos [20] utilized mixed integer programming and decomposition strategies for optimally designing offshore wind farm layouts (OWLs) considering such constraints as transformer and redundant cables requirements.

The present study not only proposes a novel approach for optimal design of wind farm layouts from mechanical, electrical and environmental points of view, but also considers all the parameters reported in the literature, such as rotor radius, hub height, collector system, cable layout, load-bearing soil and environmental restrictions, to design a realistic wind farm. These objective of the current interdisciplinary study is to create a practical guide, suitable for industry, for simulating the process of designing wind farms.

\section{Power generation model and wake effect}

\subsection{Power generation}

The generation of power from wind farms is related to the complex system of turbines placement and the layout of each wind turbine. Therefore, the wind speed and the related power produced must be assessed separately. In addition, upstream and downstream turbines affect each other. Hence to optimize wind farm designs, the wake effect and the interactions of turbines on each other should be evaluated. To determine, when modeling turbines whether they are placed in the wake front, the number of turbines, their modeling, and the distance form turbine ${ }_{j}$ have to be evaluated. Based on the impacts of turbines on each other, turbine ${ }_{i}$ has an effect on turbine ${ }_{j}$ if:

$$
\begin{aligned}
& \Delta x_{i j}>0 \quad \& \quad \sqrt{\left(\Delta y_{i j}\right)^{2}+\left(\Delta H_{i j}\right)^{2}}-\frac{D_{i}}{2}<\frac{D_{w a k e, i j}}{2} \\
& i, j=1,2, \ldots, n \quad i \neq j
\end{aligned}
$$

Conversely, $\Delta x_{i j}<0$ means that turbine ${ }_{i}$ is placed behind turbine ${ }_{j}$ :

$$
\begin{aligned}
& \Delta x_{i j}<0 \quad \& \quad \sqrt{\left(\Delta y_{i j}\right)^{2}+\left(\Delta H_{i j}\right)^{2}}-\frac{D_{j}}{2}<\frac{D_{\text {wake }, i j}}{2} \\
& i, j=1,2, \ldots, n \quad i \neq j
\end{aligned}
$$

Here, $D_{i}$ denotes the turbine ${ }_{i}$ rotor diameter and $D_{\text {wake, } i j}$ denotes the diameter of the wake resulting from turbine $e_{i}$ on turbine ${ }_{j}$.

For specifying if a turbine is exposed to the wake of other turbines, the influence matrix $K_{i j}$ is generated, where:

$$
K_{i j}=\left\{\begin{array}{l}
+1 \text { if } \text { turbine }_{i} \text { influences turbine }_{j} \\
-1 \text { if } \text { turbine }_{j} \text { influences turbine }_{i} \\
0 \text { if there is no mutual influences }
\end{array}\right.
$$


Note that $K_{i j}$ takes on values of +1 and -1 for equations 1 and 2, respectively.

To further clarify, consider Figure 3, which illustrates the case in which turbine ${ }_{k}$ is placed in front of turbine ${ }_{j}$. In this case the value of $K_{k j}$ is +1 .

Figure 3. Turbine overlap

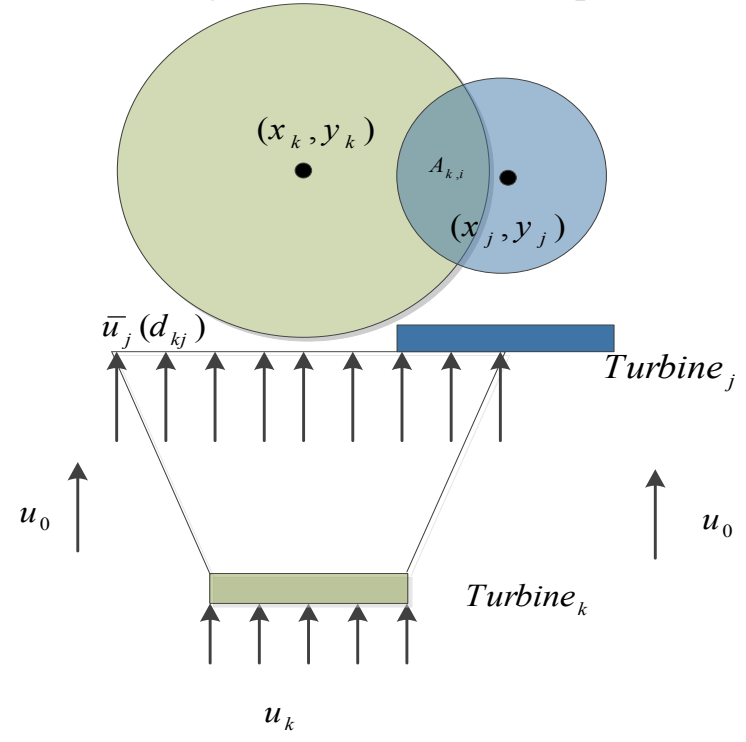

The rotor of turbine ${ }_{j}$ may be totally or partially overlapped by turbine $e_{k}$ for the first situation. The total wake-rotor overlap is assessed as follows:

$$
\sqrt{\left(y_{k}-y_{j}\right)^{2}+\left(H_{k}-H_{j}\right)^{2}} \leq r_{\text {wake }(k)}-r_{j}
$$

Here, $r_{j}$ and $r_{\text {wake }}$ denote the turbine placement in the wake effect and the radius of the spreading wake front. If the aforementioned expression is satisfied, the value of $K_{i j}$ is +1 for this condition. In other words, turbine ${ }_{j}$ is placed where the wake front is created by turbine $_{k}$. Figure 4 presents a situation in which turbine $e_{k}$ (upstream) is placed in front of turbine $e_{j}$. Then, the overlapping area is determined as follows:

$$
\begin{aligned}
& A_{k j}=A_{j} \\
& A_{j}=\pi D_{j}^{2} / 4
\end{aligned}
$$

The other situation is when turbine $e_{j}$ is partially overlapped by turbine ${ }_{k}$. Then the following inequality is satisfied

$$
r_{\text {wake }(k)}-r_{j}<\sqrt{\left(y_{k}-y_{j}\right)^{2}+\left(H_{k}-H_{j}\right)^{2}} \leq r_{\text {wake }(k)}+r_{j}
$$

and the partial wake rotor exists. Also, $K_{i j}$ takes on the value +1 in this situation, and the overlapping area can be expressed as follows: 


$$
A_{k j}=\left[r_{\text {wake }(k)}\left(d_{k j}\right)\right]^{2} \cos ^{-1}\left(\frac{L_{k j}}{r_{\text {wake }(k)}\left(d_{k j}\right)}\right)+r_{j}^{2} \cos ^{-1}\left(\frac{d_{k j}-L_{k j}}{r_{\text {wake }(k)}\left(d_{k j}\right)}\right)-d_{k j} z_{k j}
$$

To better clarify, the geometric parameters in the aforementioned expressions and their meanings are shown in Figure 4.

Figure 4. Overlap region between the rotor of a wind turbine and a wake stream.

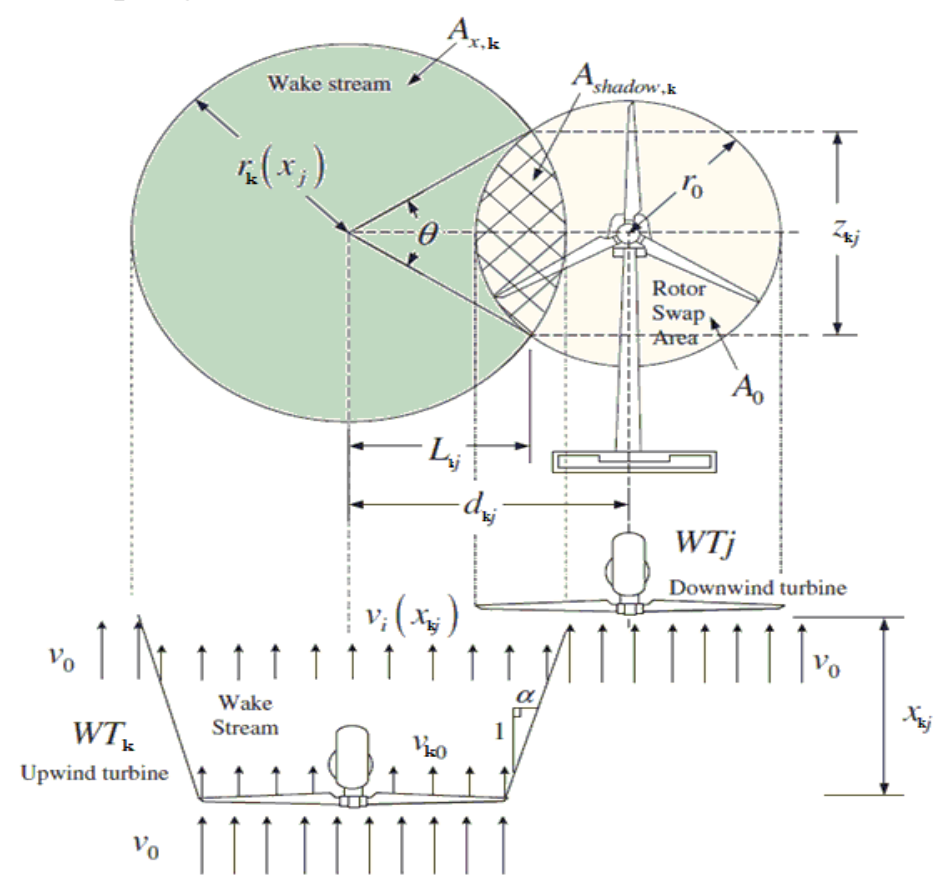

\subsection{Wake effect}

The model applied to compute the growth in each wake. The wake front growing behind turbine ${ }_{j}$ is as follows [21]:

$$
\begin{aligned}
& D_{\text {wake }, i j}=\left(1+2 \alpha s_{i j}\right) D_{i} \\
& s_{i j}=d_{i j} / D_{i}
\end{aligned}
$$

Here, $D_{\text {wake, } i j}$ denotes the diameter of the wake effect, which expands to overlap turbine ${ }_{j}$ located at a distance of $s$ behind turbine ${ }_{i}$. Also, $\alpha$ denotes the wake spreading constant, expressible as follows:

$$
\alpha=0.5 / \ln \left(\frac{Z_{H}}{Z_{0}}\right)
$$

Furthermore, $Z_{0}$ denotes the average roughness of the surface and $Z_{H}$ is the average hub height. The wake front reduces the velocity behind the turbine, although the wind speed recovers at larger distances behind the turbine. Regarding the distance traveled by the flow, the wake velocity can be expressed based on Betz theory and momentum balance as follows:

$$
\vartheta_{0}(d)=u_{0}\left[1-\left(1-\sqrt{1-C_{T}}\right)\left(\frac{D}{D+2 \alpha d}\right)^{2}\right]
$$


where $\because / d(d)$ denotes the wake velocity at distance $d, u_{0}$ the free stream wind velocity, $C_{T}$ the turbine thrust coefficient, and $D$ the turbine rotor diameter. For evaluating various upstream turbines on the $j_{t h}$ downstream, the following related expression is provided:

$$
u_{j}=u_{0}-\sqrt{\sum_{k}^{N} \frac{A_{k j}}{A_{j}}\left(u_{0}-\imath \mathcal{V}_{k j} / u_{0}\right)^{2}} \quad \forall k \stackrel{\text { yielding }}{\longrightarrow} f_{k j}=1
$$

To better illustrate, Figure 5 depicts how turbine ${ }_{j}$ is affected by turbine $e_{m, n, o}$. In this situation, turbine $_{k}$, which is upstream, has a downstream effect on turbine ${ }_{j}$, and $K_{i j}$ takes on the value +1 .

Figure 5. Deployment of turbines in each other's wake front

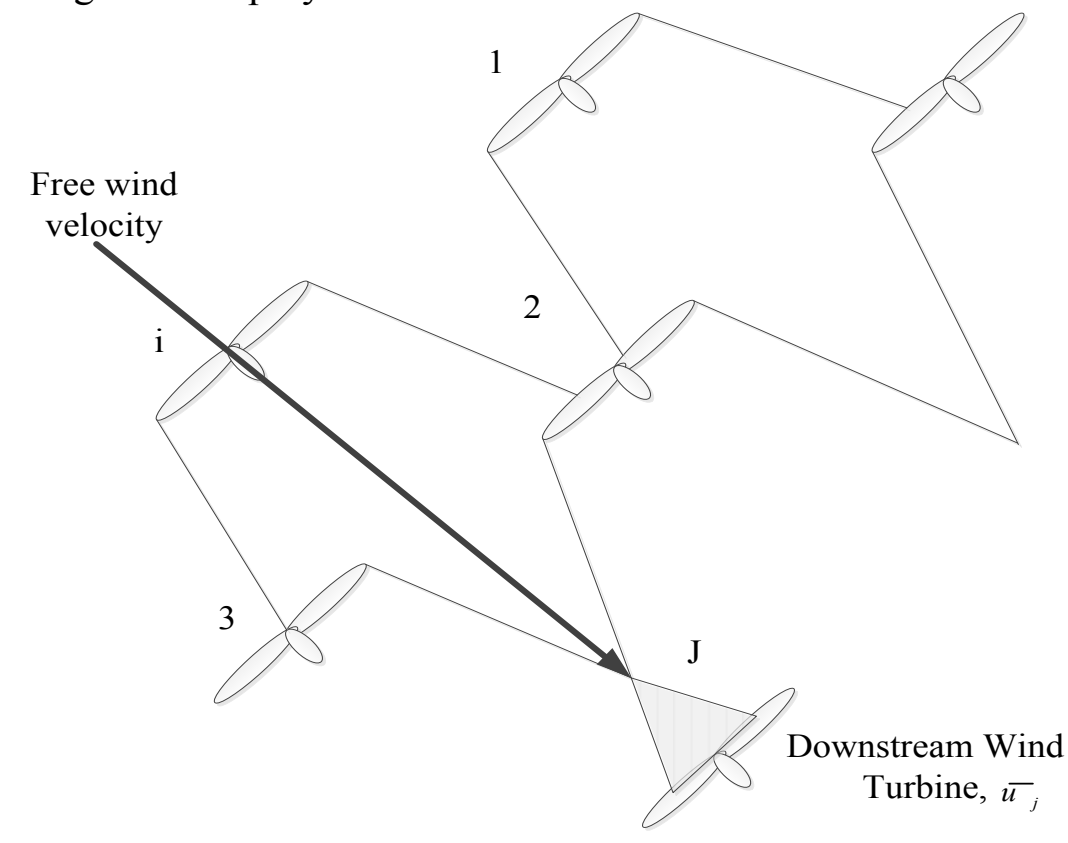

\subsection{Power analysis}

The power function is complex and impacted by various indicators. The power $\left(P_{j}\right)$ produced by turbine $_{j}$ can be expressed as follows:

$$
P_{j}=k_{e} k_{m} C_{P}^{\prime}\left(\frac{1}{2} \rho \pi \frac{D_{j}^{2}}{4} u_{j}^{3}\right)
$$

Here, $k_{e}$ denotes the generator electrical efficiency, $k_{m}$ the mechanical efficiency of the gearbox, and $C_{P}^{\prime}$ the ratio of the extracted power to the available power. The quantity $C_{P}^{\prime}$ is defined by the incoming wind speed and the tip speed ratio based on the structure of the rotor of the turbine. 


\section{Quadratic Assignment Problem (QAP)}

One of the models applied for a multi-row layout of facilities with an equal area is QAP. In this model, we consider $n$ facilities and $n$ location. A distance and a flow are determined for each pair of locations and each pair of facilities, respectively. QAP allocates facilities to varied locations in terms of minimizing the equation multiplying the total of distances by the related flows. The aim of this model is to locate the facilities with high flow near each other [22]. QAP is an non-deterministic polynomial-time hard (NP-hard) problem, so Meta-heuristic algorithms have been applied to solve this problem such as simulated annealing [23], taboo search [24] and ant colony [25]. This model involves a set $N=\{1,2,3, \ldots, n\}$ and $n \times n$ matrices. The QAP determines a permutation $\phi$ of the set $N$ which minimizes $C(\phi) . \phi_{i}$ and $\phi_{j}$ are considered the $i_{t h}$ and $j_{t h}$ elements, respectively. Then,

$$
C(\phi)=\sum_{i=1}^{n} \sum_{j=1}^{n} f_{i j} d_{\phi_{i} \phi_{j}}
$$

and $F=\left\{f_{i j}\right\}$ and $D=\left\{d_{i j}\right\}$ where $f_{i j}$ and $d_{\phi_{i} \phi_{j}}$ denote the flow and distance between facilities, from facility $_{i}$ to facility $_{j}$, respectively.

\section{Imperialistic competitive algorithm}

A global search meta-heuristic algorithm for optimization problems is the imperialistic competitive algorithm (ICA), utilizes imperialism and imperialistic competition process. The ICA is a sociopolitically motivated global search which performs like the other evolutionary algorithm (e.g. genetic algorithm (GA) and particle swarm optimization (PSO)).

The first step of this algorithm is the creation of an initial population, each individual in which is called a country. The countries which have the least cost are called imperialist and the other countries are their colonies. All the colonies are divided into imperialist with regard to their power. The fitness value is called the power of each country in ICA, which has a reverse correlation with the cost. That is, more powerful countries have a lower cost. The imperialist and their associated colonies create sets which are called empires.

The assimilation policy is next level in the ICA. This policy explains the movement of colonies toward their imperialists. After forming both initial empires and an assimilation policy, competition between empires begins. During this competition, the powerful imperialist will possess the colonies of the weakest imperialist. In this process an imperialist remains and the others collapse. Finally, an empire with the same position of colonies and imperialist will remain. [26, 27].

\subsection{Creation of initial empires}

In the problems related to optimization, discovering a global optimum solution defines a goal. An array called a country is created and it is to be optimized. In this problem, a country is considered a $1 \times N_{\text {var }}$ array, as follows:

$$
\text { Country }=\left[p_{1}, p_{2}, \ldots, p_{N_{\mathrm{var}}}\right]
$$


The variables $p_{i}$ are to be optimized. The country cost is gained via assessment of the cost function depicted as follows:

$$
\cos t=f(\text { country })=f\left(p_{1}, p_{2}, \ldots, p_{N_{\mathrm{var}}}\right) .
$$

The number of the countries is defined as $N_{\text {country }}$. Also, $N_{\text {imp }}$ are selected for the powerful countries that form the empires, and $N_{c o l}$ are chosen as the number of colonies. Initial colonies are split into the imperialist depending on their powers. An empire's initial colonies have to be allocated based on its power. To have an appropriate distribution of colonies, the cost of colonies, which is normalized, follows:

$$
C_{n}=c_{n}-\max _{i}\left\{c_{i}\right\}
$$

where $c_{n}$ denotes the cost of imperialist ${ }_{n}$ and $C_{n}$ is considered the normalized cost.

Based on the cost which is normalized for all imperialists, the normalized power can be calculated as follows:

$$
p_{n}=\left|\frac{C_{n}}{\sum_{i=1}^{N_{i m p}} C_{i}}\right|
$$

Regarding the power of initial colonies, they are split into their colonies. The quantity of colonies of empire $_{n}$ is described:

$$
N C_{n}=\operatorname{round}\left\{p_{n}, N_{c o l}\right\}
$$

where, $N C_{n}$ denotes the initial quantity of colonies of empire ${ }_{n}$ and $N_{c o l}$ the total quantity of initial colonies. To split the colonies into the imperialists, the initial number of the colonies for the empire $_{n}\left(N C_{n}\right)$ are chosen randomly, then given to the empire ${ }_{n}$. As Figure 6 shows stronger empires include more colonies than weaker ones $[26,27]$.

Figure 6. Creation of initial empires; the stronger imperialist has more colonies and a larger size ( $\star$ )

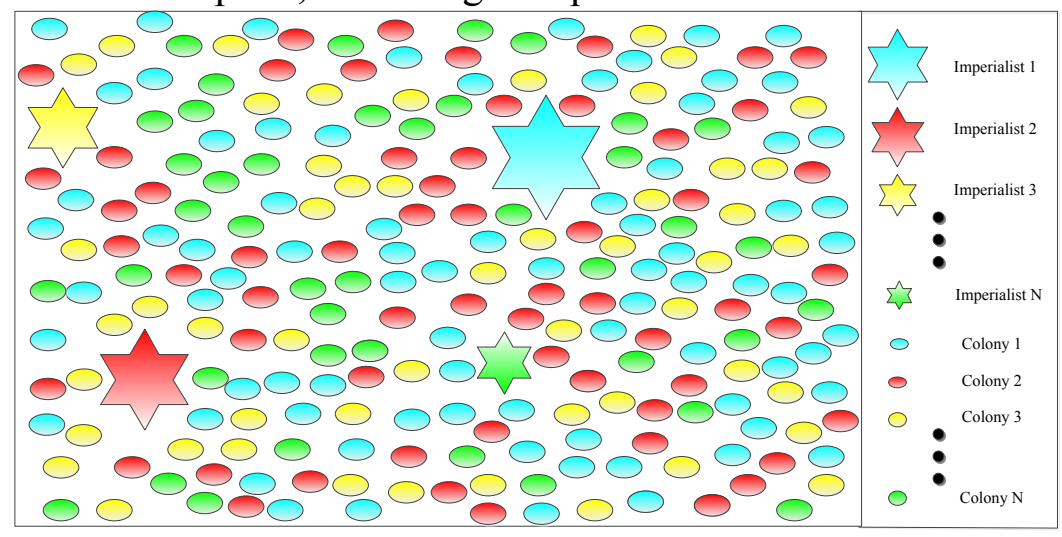

\subsection{Assimilation: colonies shifting towards the imperialists}

To optimize the colonies, the imperialists attempt to move their colonies to themselves through an assimilation policy. This movement is demonstrated in Figure 7. The colony is assimilated via two 
axes which are language and culture. The colonies attempt to move towards the imperialist. A vector illustrates the movement of a colony to the imperialist. The shifting of the colony to imperialist is shown by $x$ unit, where $x$ is considered a random variable which has a uniform distribution. That is,

$$
x: U(0, \beta \times d)
$$

Figure 7. Moving of colonies to their related imperialist

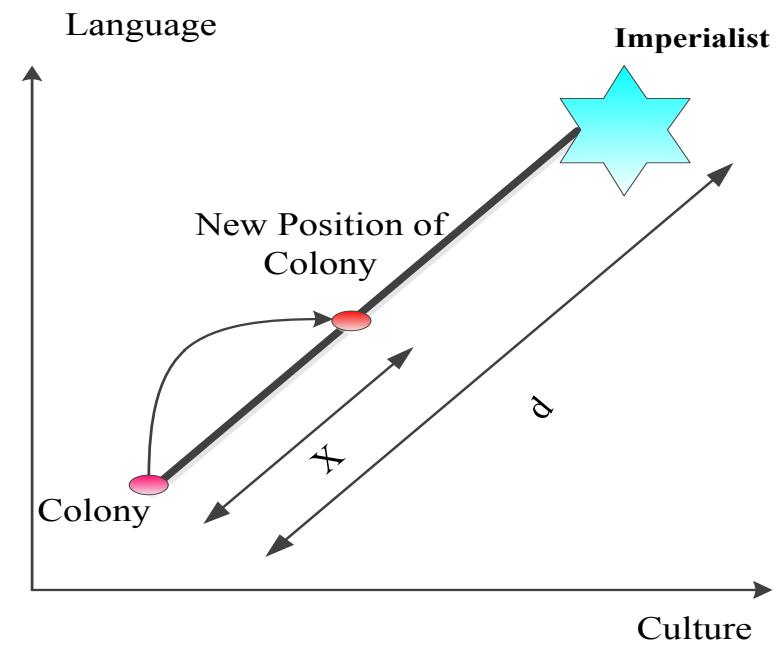

Here, the amount space of the colony and imperialist is ascertained by $d$ and $\beta$ is a number greater than 1. To get closer to the imperialists from both sides the value of $\beta$ must be greater than 1 . To get closer to the imperialists from both sides the value of $\beta$ must be greater than 1 . This kind of movement improves the solving of the problem. But for improving the exploration and ability to search more regions around the imperialist, it is necessary to add a random amount of deviation to the direction of movement, as demonstrated in Figure 8. The distribution of $\theta$ is uniform. Hence

$$
\theta: U(-\gamma, \gamma)
$$

where $\gamma$ denotes the parameter which adjusts the deviation from the original direction. Although the values of $\gamma$ and $\beta$ are considered arbitrary in most applications, the results show that values of $\pi / 4$ (radian) for $\gamma$ and 2 for $\beta$ can result in an acceptable convergence of countries for the global minimum $[26,27]$. 
Figure 8. Changing the direction of colonies to their related imperialist in an arbitrary deviated direction

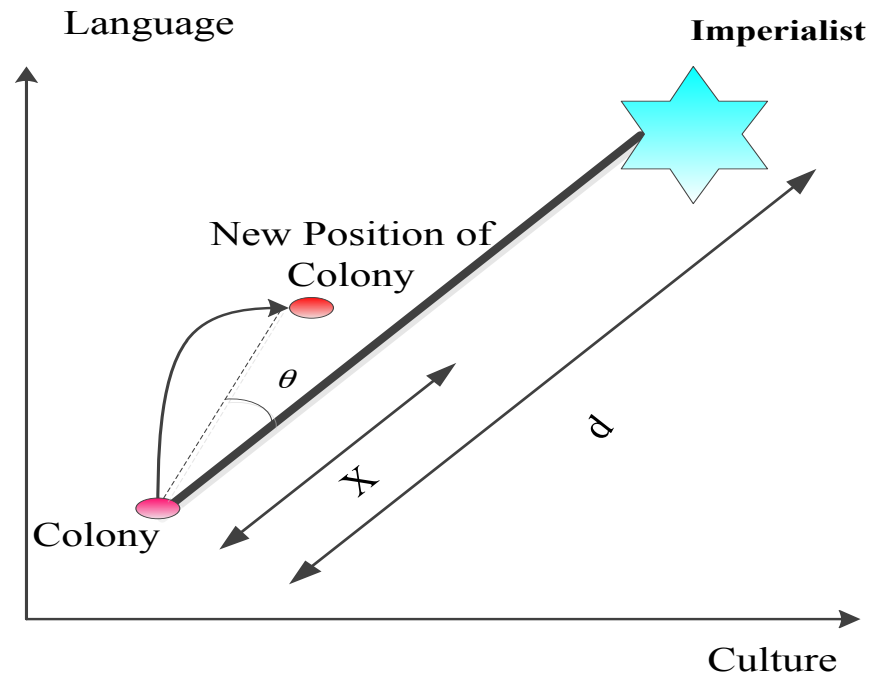

\subsection{Revolution: a dramatic change in social and political characteristic of a country}

Revolution is a kind of position changing; in this kind of changing a colony abruptly changes its socio-political characteristic. Figure 9 illustrates a revolution in the Culture-Language axis. To utilize revolution, the exploration will be increased, a process that avoids the infant convergence of countries from local minimums [26].

Figure 9. The drastic change in social and political characteristic of a country via revolution

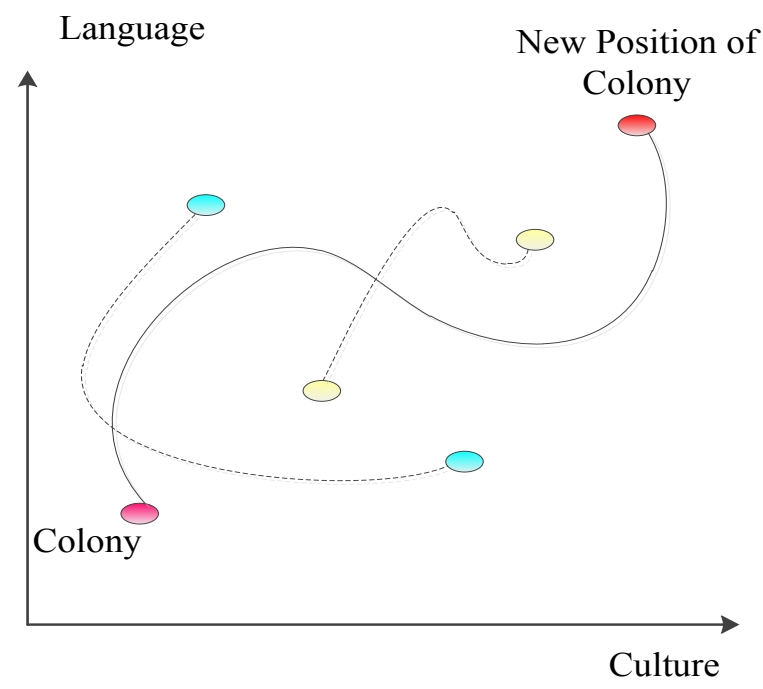

\subsection{Replacing the situation of a colony and the imperialists}

While the revolution process takes place and the colonies moving towards the imperialist, it is possible that some of the colonies attain a better situation (with lower cost) than its imperialist. The colony and its respective imperialist shift then their situations, and the ICA continues using the new imperialist and its colonies. Figures 10 and 11 demonstrate this process [27]. 
Figure 10. Entire empire after position exchange

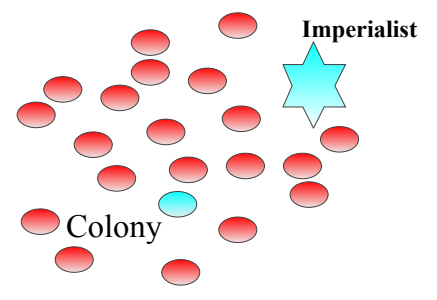

Figure 11. Exchanging the position of a colony and the imperialist

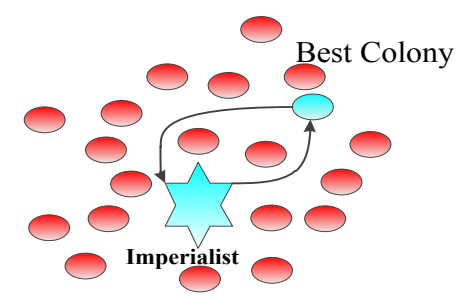

\subsection{Total power of an empire}

Although the colonies have negligible effects compared to the imperialist, the power of the imperialist country has the most influence on the total power of an empire. This can be expressed as follows:

$$
T . C \cdot_{n}=\operatorname{Cost}\left(\text { imperialist }_{n}\right)+\xi \text { mean }\left\{\text { Cost }\left(\text { colonies of the empire }{ }_{n}\right)\right\} .
$$

where $T C ._{n_{n}}$ denotes the total cost of empire ${ }_{n}$ and $\xi$ denotes a positive number which must be less than 1. Considering a little value for $\xi$ decreases the effects of the colonies on the total power but if its value increases the total power of the empire has less influence from the imperialist. Most implementations have shown 0.1 is a proper value for $\xi[27]$.

\subsection{Imperialist competition}

As mentioned above, competition among imperialists is the most significant process in the ICA. In this process all the imperialists take part in a competition to exploit other imperialist's colonies, in which the colonies of the strong imperialists will be increased and the weaker ones will lose their colonies. A schematic of the modeled imperialistic competition is demonstrated in Figure 12. This model shows the competition between all empires to possess the weakest colonies of the weakest empires. The empires compete for this colony according their power; this colony is not certain to be gained by the strongest empires, but the chance of success of these empires is high. 
Figure 12. Competition of the imperialists: the stronger empire exploits the least powerful colony associated with the least powerful empire.

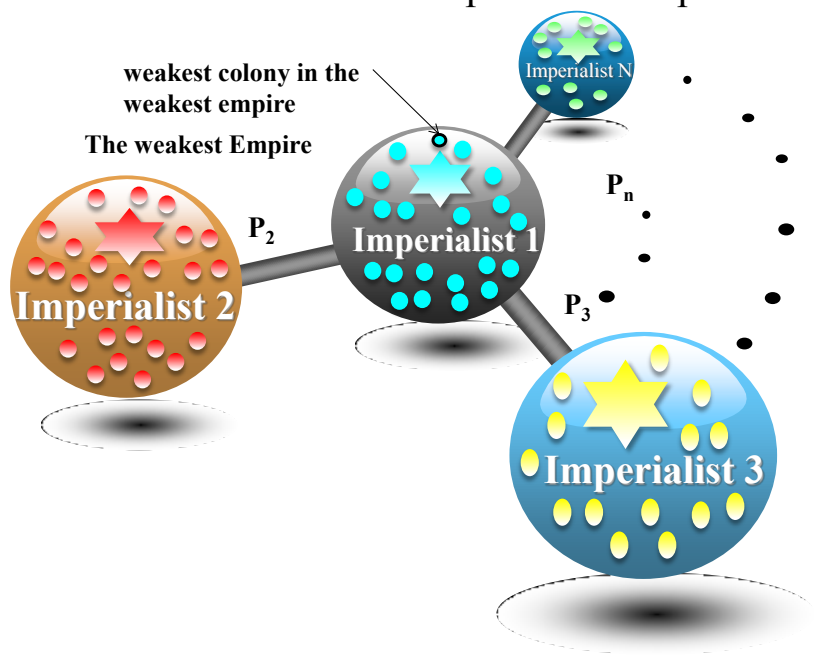

In this step we need to compute the probability of possession $\left(P_{P}\right)$ of each empire related to its total strength. The normalized total cost is calculated as follows:

$$
\text { N.T.C. }{ }_{n}=\text { T.C. }{ }_{n}-\max _{i}\left\{T_{\text {T. }}{ }_{i}\right\}
$$

Where T.C. ${ }_{n}$ denote total cost and N.T.C.n denote the normalized total cost of empire ${ }_{n}$. So the probability of the possession is calculated as follows:

$$
\mathrm{P}_{\mathrm{P}_{\mathrm{n}}}=\mid \frac{\text { N.T.C. }_{\cdot \mathrm{n}}}{\sum_{\mathrm{i}=1}^{\mathrm{N}_{\mathrm{imp}} \text { N.T.C. }{ }_{\mathrm{i}}} \mid}
$$

In the next step, for dividing the designated colonies between the empires, vector $P$ is defined:

$$
P=\left[p_{p_{1}}, p_{p_{3}}, \ldots, p_{p_{N_{\text {imp }}}}\right]
$$

Then the vector $R$ with the same size as $P$ whose elements are uniformly distributed random numbers is created:

$$
\begin{aligned}
& R=\left[r_{1}, r_{2}, r_{3}, \ldots, r_{N_{\text {imp }}}\right] \\
& r_{1}, r_{2}, r_{3}, \ldots, r_{N_{\text {imp }}}: U(0,1)
\end{aligned}
$$

Subtracting $R$ from $P$ forms vector $D$ :

$$
D=P-R=\left[D_{1}, D_{2}, D_{3}, \ldots, D_{N_{i m p}}\right]=\left[p_{p_{1}}-r_{1}, p_{p_{2}}-r_{2}, p_{p_{3}}-r_{3}, \ldots, p_{p_{N_{i m p}}}-r_{N_{i m p}}\right]
$$

The mentioned colony will be possessed by the empire that has a maximum $D$ value. $[26,27]$. 


\subsection{Eliminating the powerless empire}

In the competition of imperialists the powerless empire will collapse and its colonies will be divided among the other empires. The mechanism of eliminating an empire happens when all of its colonies are lost [27].

\subsection{Convergence}

The goal of this algorithm is defined by having the countries converge to the global minimum of the cost function. To stop the ICA we can use a distinct criteria that considers three ideas. The first includes the number of maximum decades. The second considers the end of imperialistic competition, which means the algorithm stops when there is just one empire. The last idea comprises the best solution among different solutions that cannot be improved for some number of consecutive decades $[26,27]$.

As ICA has not been used in designing layouts of turbines previously, some applications of the ICA in different research areas are introduced. Atashpaz-Gargari et al. (2008) used the ICA in the design of an optimal controller that optimally controls an industrial Multi input Multi Output (MIMO) distillation column process. Another study investigates the time estimation of product development projects, applying ICA to solve a nonlinear problem with a kind of regression [28]. An application of the ICA in heat exchangers shows in has been reported that uses the ICA to solve the optimization problem of a cross flow plate fin heat exchanger [29]. The authors improved the ICA for system reliability analyses and optimization. In another investigation, an improvement of ICA is introduced to implement an attraction and repulsion concept for reliability-redundancy optimization of systems [30].

\section{AN APPLICATION OF ICA TO SOLVE THE QUADRATIC ASSIGNMENT PROBLEM}

This study considers an area which is $(1500 \times 2500$ square meters $)$. The direction of the wind is from north to south, with an average velocity of 6.38 meter per second (at 10 meter above the ground). The data are obtained from a meteorological station in Tehran related to the Tehran Meteorological Organization (TMO). To convert the wind energy based on the height of the hub, the wind law is applied [31]. The aim is to improve the efficiency by optimal layout of 20 turbines and to decrease the wake effect to maximize the profit. Figure 13 illustrates the ICA-QAP applied to this study. 
Figure 13. Flowchart of ICA

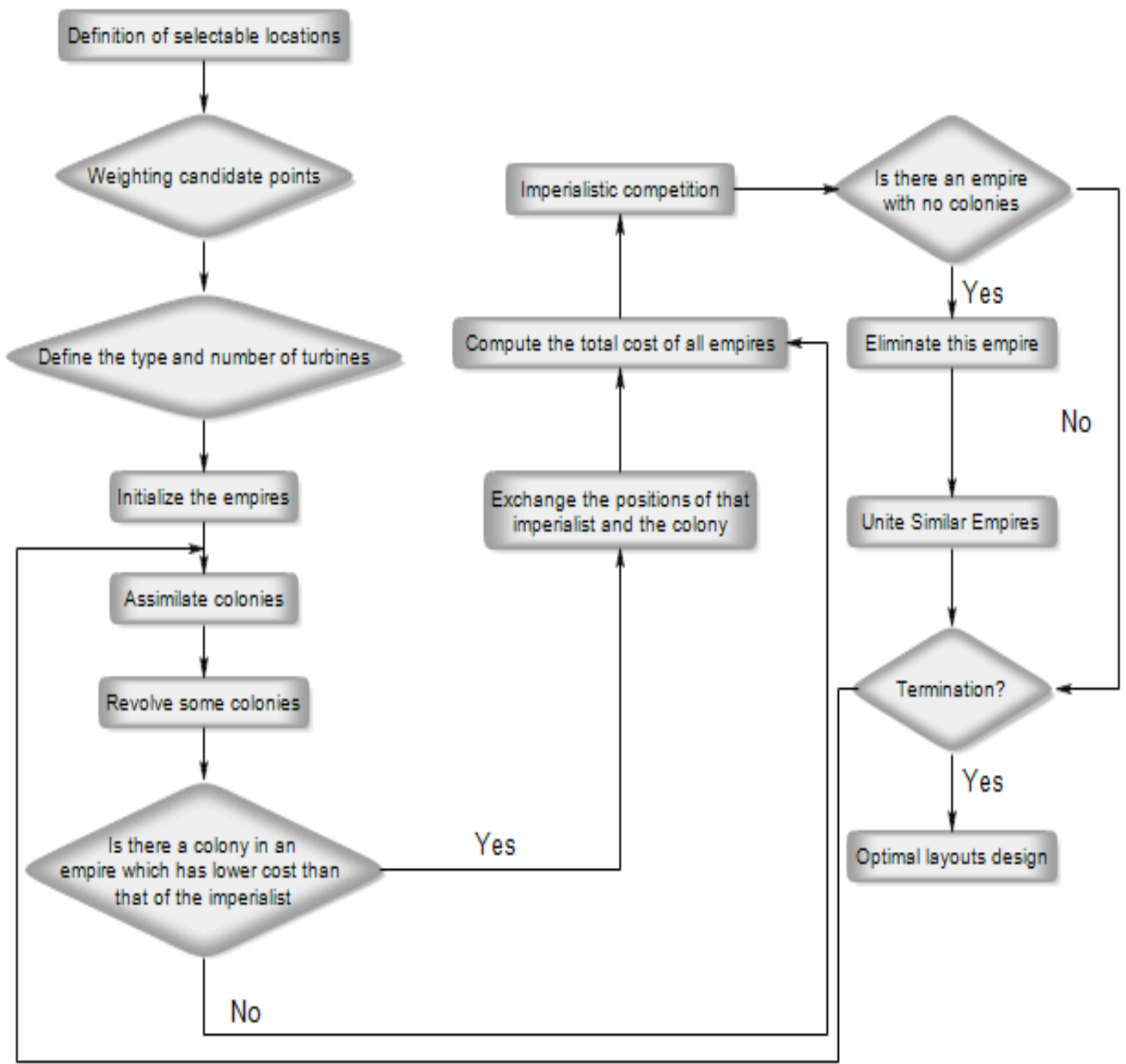

No

Even though the first placement can be done based on expert's comments, 400 initial data are generated randomly for correction with regard to the restriction and features of the land, as shown in Figure 14. Because a large number of initial points increases the computational time, the generation of initial candidate placement points is done with regard to environmental restrictions. These are the swamp and load-bearing soil that are depicted by figure 14 in which $\mathrm{X}$ and $\mathrm{Y}$ denote the length and width of the wind farm and the legend shows the weight of initial points. 
Figure 14. First locating of candidates, band point and the weighted load-bearing soil capacity

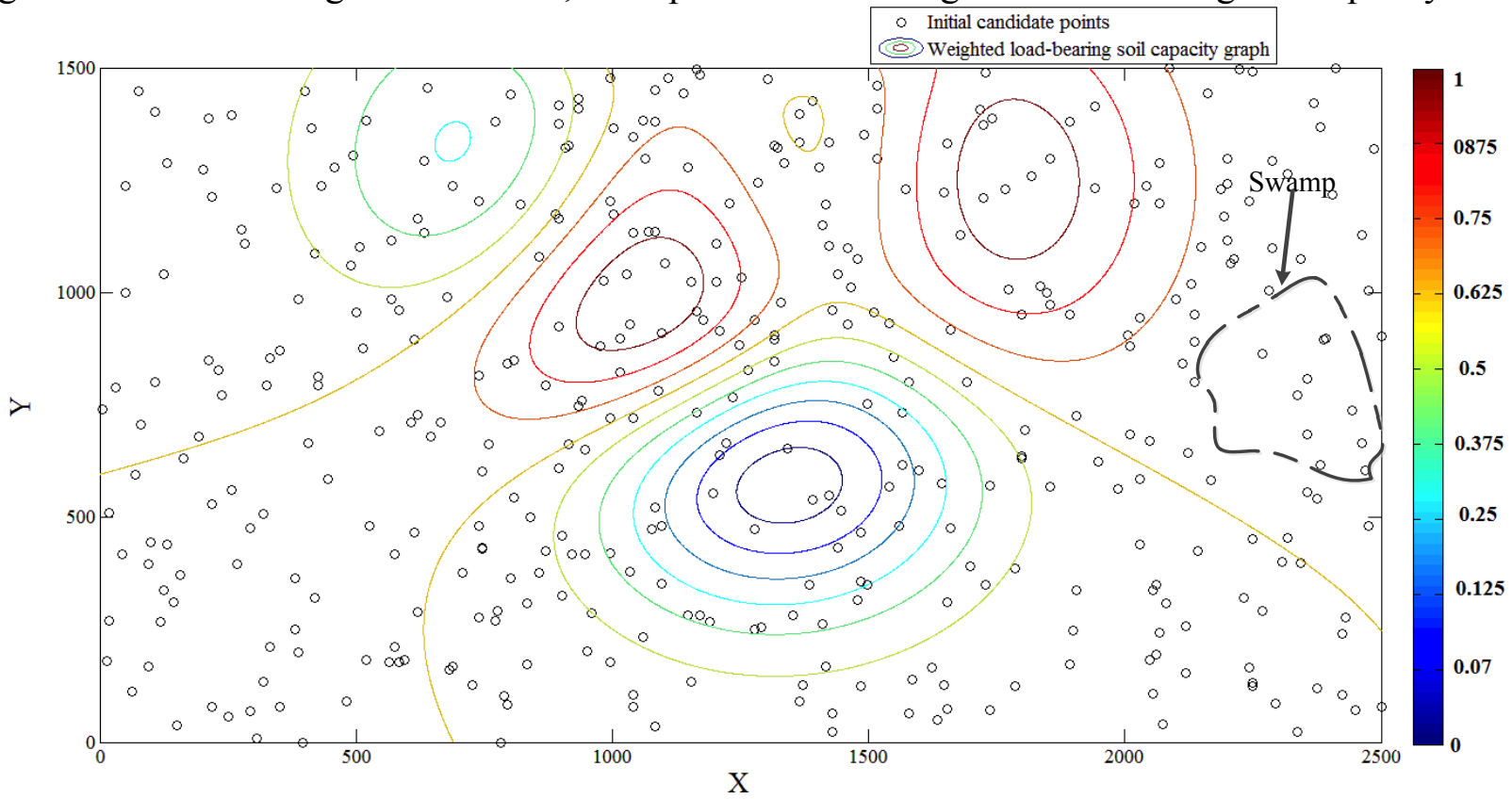

Obviously, for locations with low load-bearing soil capacity, there would be difficulties with installing or maintenance of wind turbines. To eliminate these points, they take on a zero value so as not to be selected. With regard to the limitation of some points and determining of the locations with low restriction, the weights of the points can be normalized between 0 and 1 , thus they have no units. This leads to defining the points which have lower weights than the determined threshold, which is 0.3 in this study. The points which have higher weights have better chances to be selected. However, the final selection for the locations of turbines is done based on other factors such as wake effects. Other points shown in black in figure 14 are the inputs for the process of optimization. The location matrix (LOC) which is depicted as follows introduces the data to the algorithm in a two-directional Cartesian coordinate system:

$$
L O C=\left[\begin{array}{llllll}
x_{1} & x_{2} & x_{3} & \ldots & x_{N-1} & x_{N} \\
y_{1} & y_{2} & y_{3} & \ldots & y_{N-1} & y_{N}
\end{array}\right]
$$

Different turbines with varied features are considered for the case. Tables 1 and 2 show the criteria and features of the turbines, respectively.

Table 1. Criteria for the study

\begin{tabular}{lc}
\hline Number of turbines to be placed & 20 \\
Land size $\left(\mathrm{km}^{2}\right)$ & 2.5 \\
Air density $\left(\mathrm{kg} / \mathrm{m}^{3}\right)$ & 1.066 \\
No. of considered initial choices & 400 \\
\hline
\end{tabular}


Table 2. Feature of the turbines [32]

\begin{tabular}{cccccc}
\hline $\begin{array}{c}\text { Wind } \\
\text { turbine }\end{array}$ & $\begin{array}{c}\text { Cut-in speed } \\
(\mathrm{m} / \mathrm{s})\end{array}$ & Rated speed $(\mathrm{m} / \mathrm{s})$ & Rated output $(\mathrm{kW})$ & Hub height $(\mathrm{m})$ & Rotor diameter $(\mathrm{m})$ \\
\hline D8/80 & 3 & 13.5 & 2000 & 80 & 80 \\
D6/60 & 3 & 11.5 & 1000 & 60 & 60 \\
\hline
\end{tabular}

The features of the ICA utilized for optimization are depicted in Table 3.

Table 3. Defined properties for the algorithm

\begin{tabular}{lc}
\hline Size of population & 500 \\
Number of empires & 20 \\
Number of countries & 500 \\
$\theta$ & 2 \\
Rate of revolution & 0.1 \\
Maximum number of decades & 500 \\
\hline
\end{tabular}

For designing the optimal layout of the farm, the function of efficiency is:

$$
\eta=\frac{\sum_{j=1}^{n} P_{j}}{n\left(k_{e} k_{m} C_{P}^{\prime}\left(\frac{1}{2} \rho \pi \frac{D_{j}^{2}}{4} U_{0(j)}^{3}\right)\right)}
$$

Here, $P_{j}$ depicts the power produced for turbine ${ }_{j}$ computed by the wind speed via equation (11), $\mathrm{n}$ is the number turbines, $D_{j}$ is the diameter of turbine ${ }_{j}$ and $U_{0(j)}$ denotes the incoming speed to turbine ${ }_{j}$ at the height of hub. The problem model for optimization follows:

$$
\begin{aligned}
& \text { Max } C\left(\Pi_{n}(L O C)\right)=\eta_{\text {farm }} \\
& \text { subject to } \\
& \text { LOC }=\left[\begin{array}{llllll}
x_{1} & x_{2} & x_{3} & \ldots & x_{N-1} & x_{N} \\
y_{1} & y_{2} & y_{3} & \ldots & y_{N-1} & y_{N}
\end{array}\right]
\end{aligned}
$$

where $\eta_{\text {farm }}$ is obtained from Eq. 28.

\section{Power loss}

The IEEE PES Wind Plant Collector System Design Working Group has addressed problems associated with layouts of wind farms and contributory factors such as designs of collectors, topology of feeders, which are arranging feeders and their connections, and the National Electrical Safety Code/ National Electrical Code (NESC/NEC) [33]. Moreover, Camm et al. [34, 35] have drawn up guidelines on reliability and redundancy. Dutta and Overbye [13] address the design of cables and suggest a clustering-based layout which results in more effective reliability and decreased power loss in comparison with the traditional layout, which is radial. The aim of the present paper is to decrease 
power loss by limiting lengths of cables and numbers of turbines on a feeder which are located optimally through ICA-QAP. This problem can be treated by creating a tree for satisfying the features of a graph $G=(V, B)$, where $V$ denotes the n nodes which are considered substations and locations, and $B$ denotes vertices that connect cables in the current study. To cluster the cables which are related to turbines located on a feeder, Dijkstra's Minimum Spanning Tree Algorithm and K-mean algorithms have applied.

\subsection{Dijkstra's Minimum Spanning Tree Algorithm}

A minimum spanning tree algorithm creates a tree constructed of the minimum total length between determined nodes. In this problem, the tree is deemed a graph in which there is only one path for each pair of nodes. Three sets of branches are determined by this algorithm [36]:

- First set: The branches are allocated to the tree and a subtree is formed.

- Second set: Selection of the branches which are the next branch that is added to branches from the first set.

- Third set: For the leftover branches, i.e., those which are rejected or not deemed, these data are categorized into two sets: set $A$ and $\operatorname{set} B$.

Details on these two sets follow:

- Set A: The branches of the first set that connect nodes are in this set.

- Set B: The nodes that are leftover (just one of branches of second set contribute to each of nodes) are in this set.

The initial process is to select one node as the member of set $A$ randomly. Then locating the branches completes this node and the second set. After that these two steps are redone.

- Step 1: Cutting the shortest branch of the second set and adding it to the first set. In other words, one node moves from Set $B$ to Set $A$

- Step 2: The branches obtained from the node transferred to set $A$, which are in set $B$, are deemed. If the length of branch is longer than the one in the second set, it is rejected. Otherwise, the related branch in the second set is put back and the latter is not accepted. This process is done by going back to step $I$ and the process is redone until the first and second sets become empty. The existence of branches in the first set of the tree is necessary.

\subsection{K-means clustering}

$K$ - means is considered one of the algorithms for categorizing data sets into $K$ clusters [37]. The aim is to determine $K$ centroids and to allocate each centroid to one cluster. The initial centroids have to be selected carefully because different initial locations can lead the algorithm to converge at various clusters. The centroids of the data sets are chosen in such a way that they are as far as possible from each other. After that, the data of the related points associated with the closest centroid create the clusters. The last part of the first step is to group the data together. Next, new centroids are recomputed as centers of the clusters obtained from the former step. Then the data set points are considered a group and each point is related to its closest new centroid. To reach a situation in which there are no more 
changes for the locations of the centroids, the aforementioned process continues [12]. The algorithm is described as follows:

- Step 1: $K$ points are located into the space created by the points which are being clustered. These objects show the first group centroids.

- Step 2: Each point is allocated to the group with the nearest centroid.

- Step 3: After all the points have been allocated, the situation of the $K$ centroids are recomputed.

- Steps 4: The second and the third steps are redone until the centroids are fixed without changes. This leads to a separation of the objects to cluster.

The algorithm is illustrated in Figure 15.

Figure 15. Procedure for limiting number of turbines on a feeder

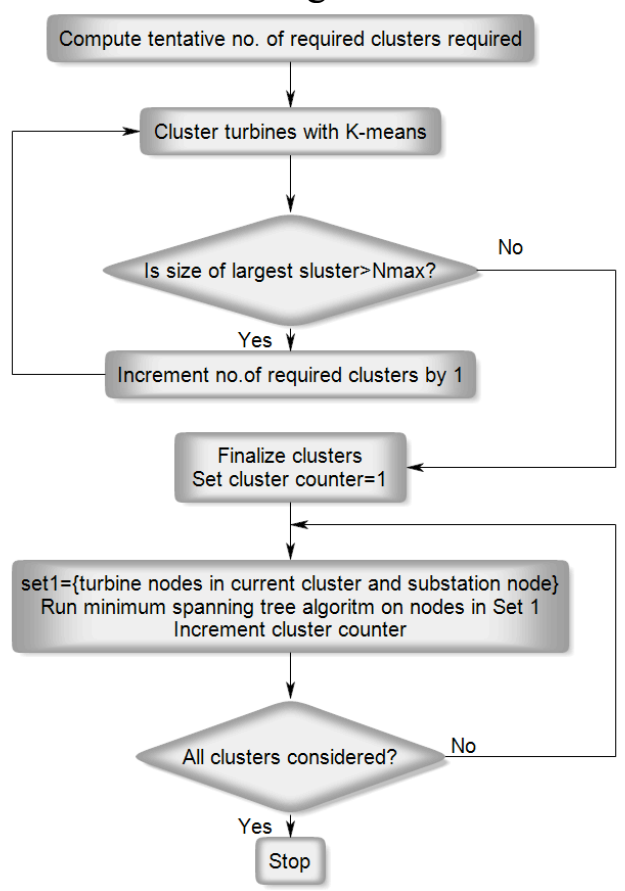

\subsection{Quantitative limitation of turbines for a feeder}

Feeder cables limit the flow carrying capacity, and constrains the quantity of turbines which can join to a feeder. Considering a constraint of $N$ max turbines on feeder, an algorithm of deigning cables to satisfy this limitation is described as follows:

- Step 1: To start the algorithm a value for the number of clusters is calculated. This value is computed by determining the ratio of number of turbines and $N \max$.

- Step 2: $K$-means clusters are obtained for the turbines and the size of the largest one is determined.

- Step 3: If the proportion of the largest cluster surpasses the predetermined $N$ max , the value of the needed numbers is raised by unity and steps 2 and 3 are repeated. Otherwise, the needed quantity of clusters is finished and the nodes of turbines are clustered by $K$ - means. 
- Step 4: In each cluster, the substation places and the nodes related to the turbines are clustered in set A. Then, the minimum spanning tree algorithm is utilized for the members of set A.

\section{Results and discussion}

\subsection{Optimal placement of wind turbines in the wind farm}

Figure 16 depicts the optimal placement of turbines based on the initial population produced randomly, which is illustrated in Figure 14. There, $\mathrm{X}$ and $\mathrm{Y}$ are the length and width of the wind farm, respectively. The stars depict the selected locations for turbines. Each selected point consists of three features: number of turbines, diameter and hub height. This algorithm tries to locate the turbines in a downstream arrangement, so they are not placed in the wake effect of upstream turbines. Moreover, based on the wind direction (north to south), fewer turbines are assigned the middle one-third (Y: 5001000 meters) in which the wake effect downstream is larger in comparison with the lower one-third (Y: 0-500 meters) and the higher one-third (Y: 1000-1500 meters). In addition, other factors such as forbidden points (swamps), restricted locations, and places with low soil-bearing capacity are avoided for selection in the optimal designed layout. Considering these factors leads the problem to be a realistic case, so, the results can be used by designers directly.

Figure 16. Optimal layout of wind turbines

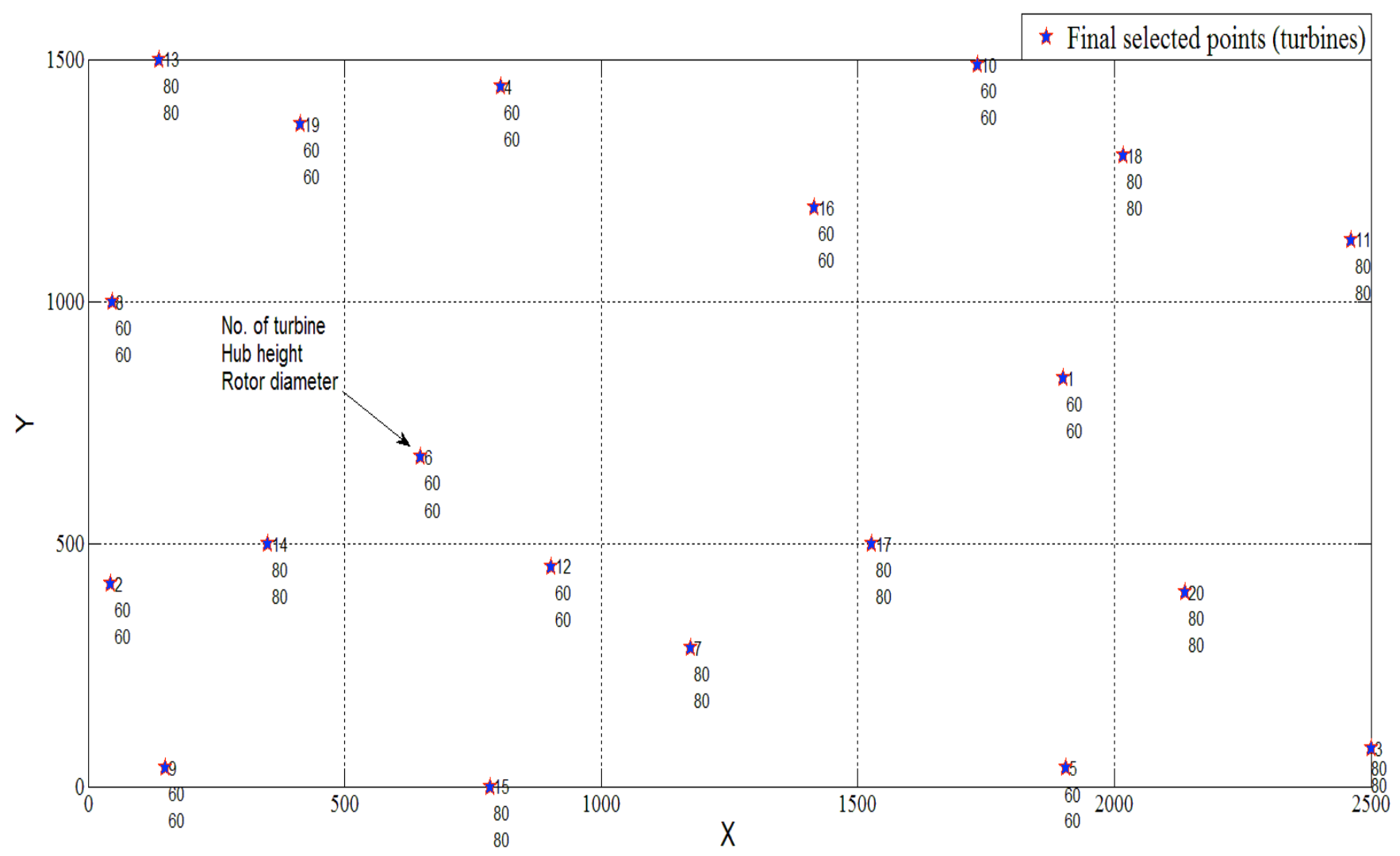


Table 4. Previous studies on placement of wind turbines

\begin{tabular}{lcc}
\hline \multicolumn{1}{c}{ Placement study } & No. of placed turbines & Efficiency (\%) \\
\hline Mosetti [38] & 26 & 91 \\
Garady [7] & 30 & 92 \\
Changshui [39] & 30 & 92 \\
Rahbari [4] & 30 & 95 \\
\hline
\end{tabular}

Table 4 shows that GA-QAP outperforms other algorithms in terms of designing of wind turbines layout. A $95.120 \%$ efficiency of power output is shown for the first case of [4]. In the first case, the authors applied GA-QAP based on the factors which are considered in similar studies and compared to the obtained results for similar studies to show the robustness of GA-QAP. Then, to obtain a more realistic design, they used the same method and considered such parameters as forbidden areas and load-bearing capacity of soil. The efficiency of the third case of the discussed study is $88 \%$ and the current study has used similar criteria and has improved the efficiency of power output more than 5 percent. As it is illustrated in Figure 17, convergence occurs after 3700 number of function evolutions (NFE) and the value of objective function for QAP-ICA is $93 \%$.

Figure 17. Procedure of ICA convergence

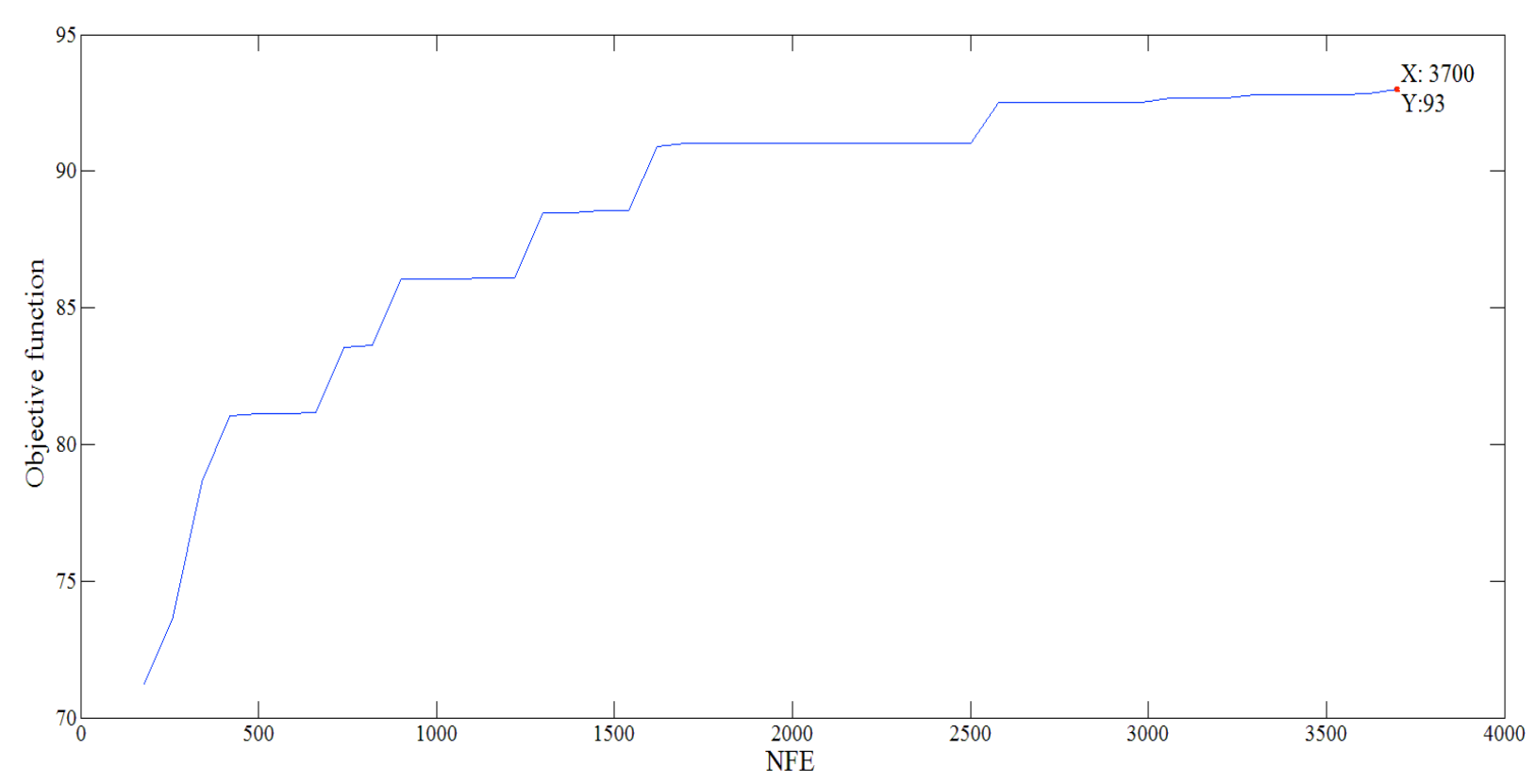

\subsection{Optimal design of wind farm collector system}

The suggested algorithm is applied on the results of the turbines for which the layout has been optimized by ICA-QAP. The case studies seek the optimal wind farm collector system involving the 20 turbines which are shown in Figure 16 (optimal designed layout).

Case 1: In this case, Dijkstra's Minimum Spanning Tree is utilized to reach the goal which is the optimal layout of cables. This algorithm is employed on the all turbines as well as for the placement of 
the substation. Along the same line, this method minimizes total length of cables without constraints of maximum quantities of turbines on each feeder. As depicted in Figure 18, there are two feeders joined to the substation and the length of cables calculated by this method is 8378 meters.

Figure 18. Shortest trenching length of cables obtained by Dijkstra's algorithm

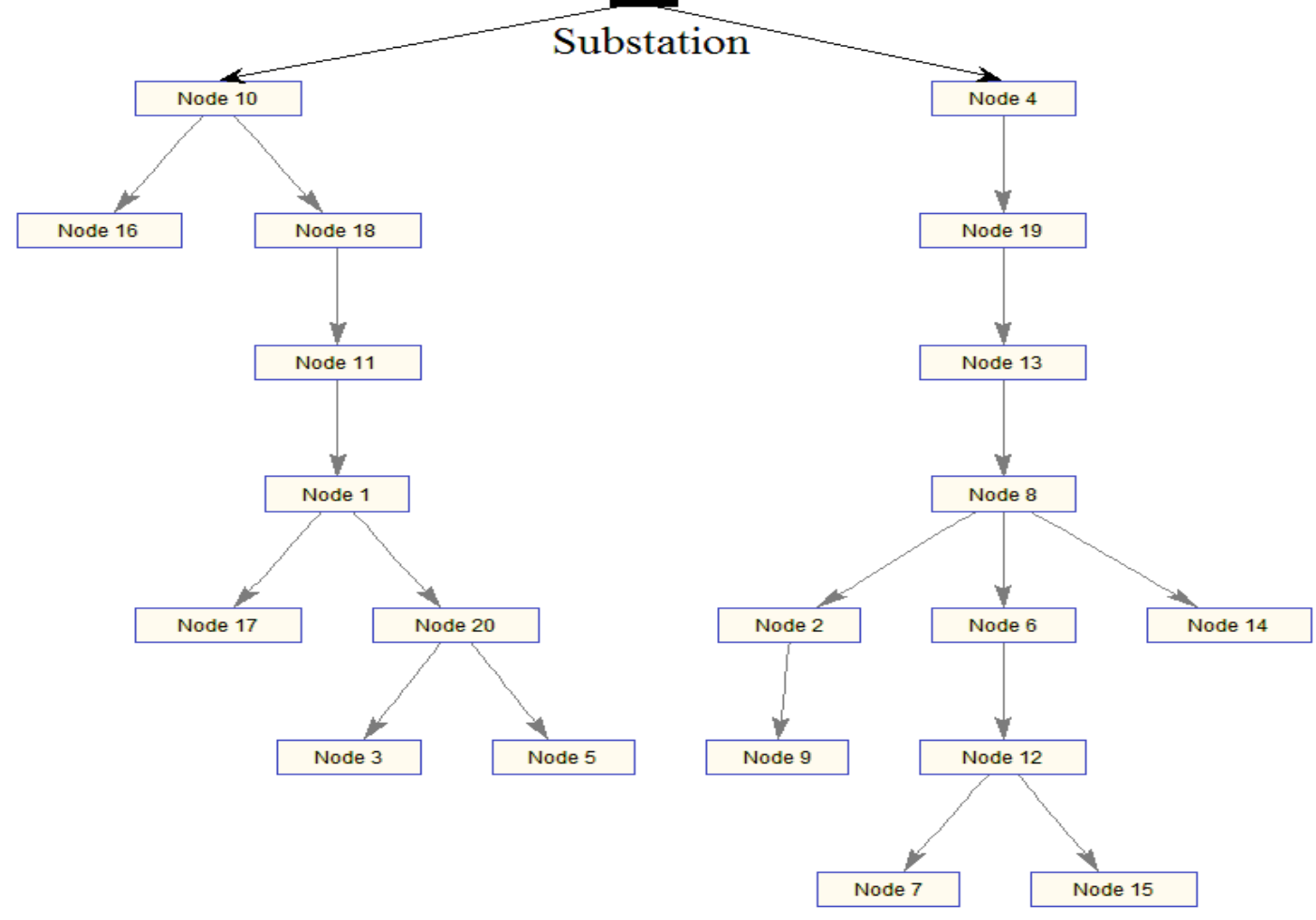

Figure 19. Three feeders each with eight or less nodes (turbines)

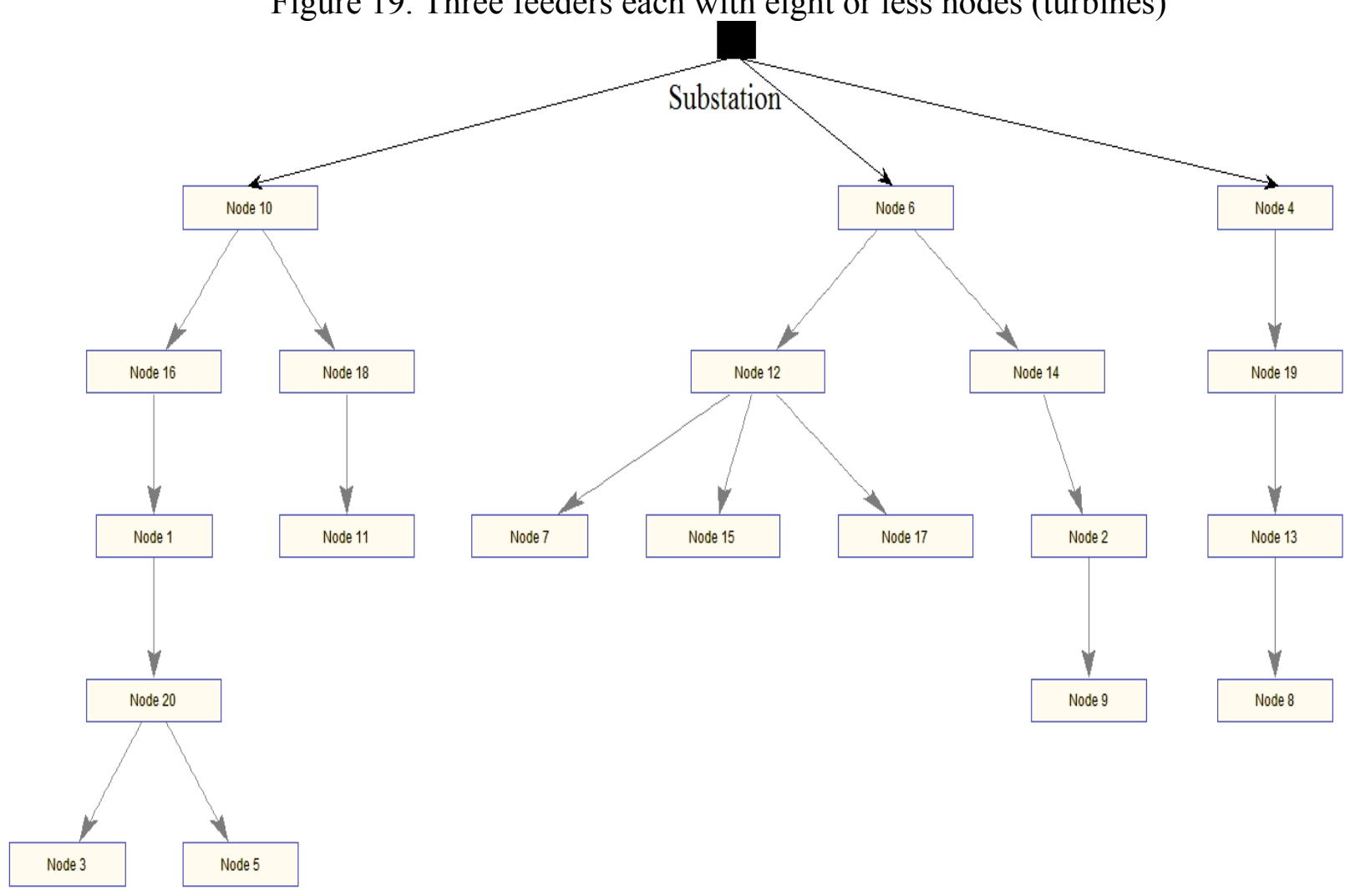


Case 2: To improve the results of Dijkstra's Minimum Spanning Tree, $K$ - mean is combined with it and the relevant combined algorithm is shown in Figure 15. This clustering considers wind turbine placement. Figure 19 shows three feeders each with eight or less nodes (turbines). In this figure, subtrees starting with node 10, node 6 and node 4 are deemed the first, second and third clusters, respectively. The quantity of clusters is specified, therefore, and the maximum quantity of turbines associated with the cluster is less than or equal to eight. In addition, the possibility of a different maximum number exists with regard to the requirement of designing. The weakness according to Figure 18 is that some turbines which are related to one branch are very close to the turbine of other branches, so it is necessary to improve the quality of algorithm to decrease the length of cables and preventing extra power loss. This hybrid algorithm results in reducing the length of cables from 8378 to 7714 meters. To illustrate better, a schematic of a design of a wind farm with regard to collector system, wind turbines and feeders is shown in figure 20 .

\section{Conclusion}

The present study proposes a hybrid imperialist competitive algorithm-quadratic assignment problem (ICA-QAP) with an initial candidate points' selection (ICPS) to search for the optimal design of wind farms layout via determining the most appropriate locations based on factors which are necessary for implementation of a real case. The results show that this algorithm improves the results by more than 5 percent in terms of efficiency compared to the highest efficiency achieved by similar studies. After addressing the optimal placement of wind turbines, a combination of Dijkstra's Minimum Spanning Tree is applied to optimize the length of the cables. This is aimed at decreasing the power loss of cables. Then, a $K$-means algorithm is combined with the previous algorithm to cluster the numbers of turbines on a feeder, which leads to the optimal design of the lengths of cables. The hybrid algorithm shows the total length of cables decreases by 664 meters. The design steps using the proposed approaches can be considered as a method for a) incorporating expert preferences into the final layout, b) achieving optimal turbine placement so as to achieve high performance farms and shift towards energy sustainability, and c) attaining economic benefits by reducing power losses and decreasing the required cable lengths. Applying the examined approaches under variable wind speed and direction conditions merits further investigation as an extension of the conducted study.

\section{References}

[1] World Wind Energy Association WWEA, report. Bonn, Germany, 2011.

[2] D. A. Digraskar, "Simulations of flow over wind turbines," Master of Science in Mechanical Engineering (M.S.M.E.), University of Massachusetts Amherst, 2010.

[3] F. González-Longatt, P. Wall, and V. Terzija, "Wake effect in wind farm performance: Steadystate and dynamic behavior," Renewable Energy, vol. 39, pp. 329-338, 2012.

[4] O. Rahbari, M. Vafaeipour, F. Fazelpour, M. Feidt, and M. A. Rosen, "Towards realistic designs of wind farm layouts: Application of a novel placement selector approach," Energy Conversion and Management, vol. 81, pp. 242-254, 2014.

[5] S. Salcedo-Sanz, D. Gallo-Marazuela, A. Pastor-Sánchez, L. Carro-Calvo, A. Portilla-Figueras, and L. Prieto, "Evolutionary computation approaches for real offshore wind farm layout: A 
case study in northern Europe," Expert Systems with Applications, vol. 40, pp. 6292-6297, 2013.

[6] B. Saavedra-Moreno, S. Salcedo-Sanz, A. Paniagua-Tineo, L. Prieto, and A. Portilla-Figueras, "Seeding evolutionary algorithms with heuristics for optimal wind turbines positioning in wind farms," Renewable Energy, vol. 36, pp. 2838-2844, 2011.

[7] S. Grady, M. Hussaini, and M. M. Abdullah, "Placement of wind turbines using genetic algorithms," Renewable Energy, vol. 30, pp. 259-270, 2005.

[8] B. Pérez, R. Mínguez, and R. Guanche, "Offshore wind farm layout optimization using mathematical programming techniques," Renewable Energy, vol. 53, pp. 389-399, 2013.

[9] Y. Eroğlu and S. U. Seçkiner, "Design of wind farm layout using ant colony algorithm," Renewable Energy, vol. 44, pp. 53-62, 2012.

[10] A. Miller, E. Muljadi, and D. S. Zinger, "A variable speed wind turbine power control," IEEE Transactions on Energy Conversion, vol. 12, pp. 181-186, 1997.

[11] H. Lee Willis, H. Tram, M. V. Engel, and L. Finley, "Optimization applications to power distribution," Computer Applications in Power, IEEE, vol. 8, pp. 12-17, 1995.

[12] S. Dutta and T. J. Overbye, "Optimal wind farm collector system topology design considering total trenching length," IEEE Transactions on Sustainable Energy, vol. 3, pp. 339-348, 2012.

[13] S. Dutta and T. J. Overbye, "A clustering based wind farm collector system cable layout design," in 2011 IEEE Power and Energy Conference at Illinois (PECI), 2011, pp. 1-6.

[14] H.-P. Cheng and M.-T. Yu, "Effect of the transmission configuration of wind farms on their capacity factors," Energy Conversion and Management, vol. 66, pp. 326-335, 2013.

[15] M. Garcia-Gracia, M. P. Comech, J. Sallan, and A. Llombart, "Modelling wind farms for grid disturbance studies," Renewable Energy, vol. 33, pp. 2109-2121, 2008.

[16] H. Jadhav and R. Roy, "Effect of turbine wake on optimal generation schedule and transmission losses in wind integrated power system," Sustainable Energy Technologies and Assessments, vol. 7, pp. 123-135, 2014.

[17] F. Deng and Z. Chen, "An offshore wind farm with DC grid connection and its performance under power system transients," in 2011 IEEE Power and Energy Society General Meeting, 2011, pp. 1-8.

[18] L. Meegahapola, S. Abbott, D. Morrow, T. Littler, and D. Flynn, "Optimal allocation of distributed reactive power resources under network constraints for system loss minimization," in 2011 IEEE Power and Energy Society General Meeting, 2011, pp. 1-7.

[19] E. Saiz-Marin, E. Lobato, I. Egido, and L. Rouco, "Power losses minimization within Spanish wind farms evacuation networks," in 2013 IEEE Power and Energy Society General Meeting, 2013, pp. 1-5.

[20] S. Lumbreras and A. Ramos, "Optimal design of the electrical layout of an offshore wind farm applying decomposition strategies," IEEE Transactions on Power Systems, vol. 28, pp. 14341441, 2013.

[21] S. Frandsen, R. Barthelmie, S. Pryor, O. Rathmann, S. Larsen, J. Højstrup, et al., "Analytical modelling of wind speed deficit in large offshore wind farms," Wind energy, vol. 9, pp. 39-53, 2006.

[22] E. L. Lawler, "The quadratic assignment problem," Management Science, vol. 9, pp. 586-599, 1963.

[23] M. R. Wilhelm and T. L. Ward, "Solving quadratic assignment problems by 'simulated annealing,", IIE Transactions, vol. 19, pp. 107-119, 1987.

[24] E. Taillard, "Robust taboo search for the quadratic assignment problem," Parallel Computing, vol. 17, pp. 443-455, 1991.

[25] L. M. Gambardella, E. Taillard, and M. Dorigo, "Ant colonies for the quadratic assignment problem," Journal of the Operational Research Society, pp. 167-176, 1999.

[26] S. Nazari-Shirkouhi, H. Eivazy, R. Ghodsi, K. Rezaie, and E. Atashpaz-Gargari, "Solving the integrated product mix-outsourcing problem using the Imperialist Competitive Algorithm," Expert Systems with Applications, vol. 37, pp. 7615-7626, 2010. 
[27] E. Atashpaz-Gargari and C. Lucas, "Imperialist Competitive Algorithm: An algorithm for optimization inspired by imperialistic competition," IEEE Congresson Evolutionary Computation, pp. 4661-4667, 2007.

[28] S. M. Mousavi, R. Tavakkoli-Moghaddam, B. Vahdani, H. Hashemi, and M. J. Sanjari, "A new support vector model-based imperialist competitive algorithm for time estimationin new product development projects," Robotics and Computer-Integrated Manufacturing, vol. 29, pp. 157-168, 2013.

[29] M. Yousefi, A. N. Darus, and H. Mohammadi, "An imperialist competitive algorithm for optimal design of plate-fin heat exchangers," International Journal of Heat and Mass Transfer, vol. 55, pp. 3178-3185, 2012.

[30] L. D. Afonso, V. C. Mariani, and L. D. S. Coelho, "Modified imperialist competitive algorithm based on attraction and repulsion concepts for reliability-redundancy optimization," Expert Systems with Applications, vol. 40, pp. 3794-3802, 2013.

[31] A. Dahmouni, M. Ben Salah, F. Askri, C. Kerkeni, and S. Ben Nasrallah, "Assessment of wind energy potential and optimal electricity generation in Borj-Cedria, Tunisia," Renewable and Sustainable Energy Reviews, vol. 15, pp. 815-820, 2011.

[32] M. M. Alam, S. Rehman, J. P. Meyer, and L. M. Al-Hadhrami, "Review of 600-2500kW sized wind turbines and optimization of hub height for maximum wind energy yield realization," Renewable and Sustainable Energy Reviews, vol. 15, pp. 3839-3849, 2011.

[33] E. Camm, M. Behnke, O. Bolado, M. Bollen, M. Bradt, C. Brooks, et al., "Wind power plant collector system design considerations: IEEE PES wind plant collector system design working group," in 2009 IEEE Power and Energy Society General Meeting, 2009, pp. 1-7.

[34] E. Camm, M. Behnke, O. Bolado, M. Bollen, M. Bradt, C. Brooks, et al., "Wind power plant grounding, overvoltage protection, and insulation coordination: IEEE PES wind plant collector system design working group," in 2009 IEEE Power and Energy Society General Meeting, 2009, pp. 1-8.

[35] E. Camm, M. Behnke, O. Bolado, M. Bollen, M. Bradt, C. Brooks, et al., "Wind power plant substation and collector system redundancy, reliability, and economics," in 2009 IEEE Power and Energy Society General Meeting, 2009, pp. 1-6.

[36] E. W. Dijkstra, "A note on two problems in connexion with graphs," Numerische mathematik, vol. 1, pp. 269-271, 1959.

[37] J. MacQueen, "Some methods for classification and analysis of multivariate observations," in Proceedings of the Fifth Berkeley Symposium on Mathematical Statistics and Probability, 1967, pp. 281-297.

[38] G. Mosetti, C. Poloni, and B. Diviacco, "Optimization of wind turbine positioning in large windfarms by means of a genetic algorithm," Journal of Wind Engineering and Industrial Aerodynamics, vol. 51, pp. 105-116, 1994.

[39] Z. Changshui, H. Guangdong, and W. Jun, "A fast algorithm based on the submodular property for optimization of wind turbine positioning," Renewable Energy, vol. 36, pp. 2951-2958, 2011. 